Original Article

\title{
Effects of gait training on sand on improving the walking ability of patients with chronic stroke: a randomized controlled trial
}

\author{
TAe-Ho Kim, PhD, $\mathrm{PT}^{1)}$, Byoung-Ha Hwang, MSc, PT ${ }^{1 *}$ \\ 1) Department of Physical Therapy, College of Rehabilitaion Science, Daegu University: \\ 201 Daegudae-ro, Jillyang, Gyeongsan, Gyeongbuk, Republic of Korea
}

\begin{abstract}
Purpose] This study examines how difference in sandy ground between firm ground influences the effects of gait training in patients with chronic stroke. [Subjects and Methods] A total of 28 patients with chronic stroke were evenly divided into experimental and control groups. Initial evaluation of the subjects was conducted by Timed Up \& Go (TUG) and 6-Minute Walking Test (6MWT). Each patient in both groups received daily, 30-minute gait training on sandy ground and firm ground, five times each week, for a total of six weeks, after which reevaluation was conducted. [Results] In TUG, both groups showed significant improvement after the intervention. In 6MWT, only the experimental group achieved significantly increased distance after the intervention. However, there was no between-group difference. Improvement in dynamic balancing ability depends on repeated gait training rather than differences in the ground environment. However, gait endurance showed a difference depending on the types of ground, regardless of repeated gait training. [Conclusion] This can be attributed to the fact that gait training on sand requires use of more diverse muscles. Hence, we can confirm the potential of sand as a new material for training ground when attempting to improve walking ability, particularly gait endurance, among patients with chronic stroke.

Key words: Gait training, Stroke, Sand gait
\end{abstract}

(This article was submitted Jul. 30, 2017, and was accepted Sep. 20, 2017)

\section{INTRODUCTION}

Patients with stroke experience many challenges after the onset. Approximately $60 \%$ of patients with stroke suffer from weakened motor ability, and about half of patients with stroke require assistance from other people in their daily lives. Most are capable of limited participation in social or work activities ${ }^{1,2)}$. One of the most serious challenges is diminished balancing ability and decrease or loss of walking ability, resulting from the loss of control'3).

Walking ability does not simply refer to movement of the body. From the perspective of the International Classification of Functioning, Disability and Health (ICF), walking in patients with stroke should be assessed by integrating disability, activity, participation, and quality of life ${ }^{4}$. Gait training that simply aims at restoring patients' ability to walk is insufficient. For most patients, the goal is not simply walking, but achieving walking ability that allows them to return to active participation in the community. Hence, recovery of walking ability is the primary goal when planning treatment for patients with stroke ${ }^{5}$.

Therefore, there are a number of approaches aimed at enhancing walking ability in patients with stroke. However, most previous literature involves intervention schemes that do not duplicate the actual walking environment encountered by patients in everyday life. Thus, an approach to gait training that involves a varied ground environment is necessary.

Gait training on unstable ground instead of firm ground requires more diverse movement in the ankle joint as well as large muscle strength ${ }^{6}$. Using such environmental characteristics can induce greater ankle mobility and improvement of

*Corresponding author. Byoung-ha Hwang (E-mail: ptkimth@daegu.ac.kr)

(C2017 The Society of Physical Therapy Science. Published by IPEC Inc.

(c) (1) $\odot$ This is an open-access article distributed under the terms of the Creative Commons Attribution Non-Commercial No Deriva-

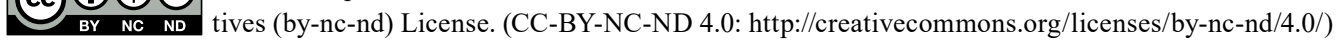


proprioception. The increased proprioception is effective for enhancing walking ability, as it increases muscle strength and balancing ability in the affected-side ankle of patients with stroke ${ }^{7)}$. This study chose sand ground instead of firm ground as a new environment for gait training.

Virtually none of the previous studies used sandy ground for rehabilitating patients with chronic stroke. However, several studies used sand as a training method for improving athletic performance in athletes.

A study that implemented plyometrics training on sand as a means of improving athletic performance, such as jumping and sprinting among football players, reported improved athletic performance, including jumping and changing directions ${ }^{8)}$. Another study reported that muscle injury is less likely when training on sand versus firm ground, due to the characteristics of sand ${ }^{9)}$. Binnie et al. reported that eight-week sand training was effective in improving Maximal Oxygen Uptake (VO2max) and that self-awareness of pain and fatigue during training were lower on sandy ground than firm ground ${ }^{10)}$. This study attempted to determine the effects of the walking ability by applying the sandy ground to gait training for patients with chronic stroke.

\section{SUBJECTS AND METHODS}

A total of 30 subjects participated in this study, two of whom were discharged from the hospital during the intervention period, making the total number of research subjects for the experiment 28 .

After explaining the purpose of this study to the patients with chronic stroke who were hospitalized for treatment, those who submitted voluntary consent and expressed their willingness to participate were randomly assigned to the experimental group or control group. The patients who were capable of independent walking, including those who used a walking aid and had no musculoskeletal disease or cognitive problem, were selected as the research subjects.

This study received Institutional Review Board approval from Daegu University (1040621-201507-HR-003-02).

The walking ability of the two groups was evaluated before the experiment by Timed Up \& Go evaluation and 6-Minute Walking Test. The two tests were implemented on different days, so that they did not affect the other's results. Through the data collected, the homogeneity of the two subject groups was confirmed. During the daily 30-minute gait training, which occurred five times each week for a total of six weeks, the control group received gait training on firm ground and the experimental group received gait training on sand. The control group performed gait training on regular, firm ground, inside a treatment room, with shoes on. The thin shoes was worn to prevent foot damage by friction of the floor. The experimental group performed gait training on sand, inside a treatment room, with bare feet. The sandy ground was specially made at a width of 1 meter, a length of 5 meters, and a depth of 30 centimeters.

No restrictions were put on the walking methods of either group, so that each individual could use the walking habits and strategy that he/she relearned after the occurrence of stroke. If necessary, the use of a walking aid, such as a cane, was allowed. Interventions other than walking were prohibited, to exclude additional training influences aside from the environmental characteristics of the walking ground.

To evaluate walking ability, TUG was measured three times, and the average of the three values was used. TUG is an assessment tool that evaluates dynamic balancing ability. It has a proven reliability, with intra-rater reliability of $r=0.99$ and inter-rater reliability of $\mathrm{r}=0.98^{11}$.

6MWT was measured only once, due to the characteristics of the subjects, and the subjects were encouraged to make their greatest efforts during the measurement. The 6MWT is also a tool that evaluates gait endurance among hemiplegic patients or those with cardiopulmonary disease. It has proven validity and reliability when applied to patients with stroke ${ }^{12)}$.

As the collected data were not in normal distribution, data were statistically analyzed through a non-parametric test. Within-group comparison before and after the intervention was conducted by Wilcoxon signed rank test and between-groups difference, according to the intervention scheme, was analyzed by Mann Whitney U test. All data were statistically analyzed using SPSS version 20.0, where significance level was set at less than 0.05 .

\section{RESULTS}

In TUG, both groups showed a significant difference after the intervention. In 6MWT, only the sandy ground training group showed a significant difference after the intervention. However, neither variable showed a statistically significant between-group difference before or after the intervention (Tables 1 and 2).

\section{DISCUSSION}

This study attempted to identify the effects of difference in ground environment on improving walking ability in patients with chronic stroke.

In the TUG evaluation of dynamic stability, both groups showed decreased performance time after the intervention. However, there was no between-group difference. This implies that the repeated gait training increased dynamic stability, regardless of the difference in the ground.

In 6MWT, which evaluated gait endurance, only the sandy ground training group showed a significant improvement. This 
Table 1. General characteristic of the subject $(n=28)$

\begin{tabular}{lcc}
\hline & Experimental group & Control group \\
\hline Gender (male/female) & $14(6 / 8)$ & $14(5 / 9)$ \\
Age (years) & $69.0 \pm 10.0^{\mathrm{a}}$ & $71.3 \pm 10.5$ \\
Height $(\mathrm{cm})$ & $162.4 \pm 5.7$ & $161.8 \pm 7.7$ \\
Weight $(\mathrm{kg})$ & $61.5 \pm 8.1$ & $65.9 \pm 15.3$ \\
Onset time (months) & $21.0 \pm 13.7$ & $32.1 \pm 10.5$ \\
Hemi side (right/left) & $8 / 6$ & $7 / 7$ \\
\hline
\end{tabular}

${ }^{\mathrm{a}} \mathrm{M} \pm \mathrm{SD}:$ Mean \pm standard deviation.

Table 2. Comparison of walking ability evaluation before and after the intervention $(n=28)$

\begin{tabular}{llcc}
\hline & Group & Pre-test & Post-test \\
\hline TUG & Experimental group & $27.6 \pm 15.7^{\mathrm{a}}$ & $21.5 \pm 13.2^{*}$ \\
(seconds) & Control group & $30.9 \pm 18.5$ & $27.7 \pm 18.2^{*}$ \\
6MWT & Experimental group & $162.0 \pm 148.9$ & $204.9 \pm 158.3^{*}$ \\
(meters) & Control group & $159.5 \pm 124.0$ & $182.7 \pm 131.1$ \\
\hline
\end{tabular}

${ }^{\mathrm{a}} \mathrm{M} \pm \mathrm{SD}:$ Mean \pm standard deviation.

*Significant difference $\mathrm{p}<0.05$.

implies that sandy ground training is more effective at enhancing gait endurance than firm ground training. Improvement of gait endurance is determined by diverse physical factors, including muscle strength, muscle endurance, and cardiopulmonary endurance. Similar to the results in Yiğit et al., it is conjectured that muscle strength and muscle endurance of the calf and thigh improved after the sandy ground training ${ }^{13}$. Moreover, Davies and Mackinnon reported that maximal oxygen uptake, heart rate, and ventilation volume of oxygen and carbon dioxide increased during walking on sand ${ }^{14)}$. Assuming the same distance, this implies that walking on sand induces more use of cardiopulmonary function than other ground conditions. In this study, it is conjectured that the repeated gait training on sand improved not only muscle strength and muscle endurance, but also cardiopulmonary function, compared to training on firm ground. This ultimately enhanced gait endurance.

This study did not directly assess the mobility of the affected-side ankle joint of the hemiplegic patients. However, it is conjectured that training on sand induced enhancement of ankle function of the hemiplegic patients, consequently improving their balancing and walking. Impellizzeri et al. examined the improvement of jumping function of volleyball players after training on sand. According to their study results, players have to thrust their ankle more forcefully when jumping on sand, as their feet slip on sand. In this type of situation, more joint mobility and muscle groups are used, due to the stretchshortening cycle of the muscles surrounding the ankle. This increases the angular velocity of the ankle, improving the jumping function ${ }^{8}$. Our study did not implement high-level motion, such as jumping, due to the characteristics of the subjects. Nevertheless, gait training on sand improved ankle mobility and nerve roots control, thanks to the stretch-shortening cycle of the muscles surrounding the affected-side ankle joint, which is difficult to voluntarily control. This generated mobility that is necessary for walking, which consequently helped gait endurance. Pinnington and Dawson reported that training on sand causes lower accumulation of lactic acid and reduces the metabolic fatigue that results from muscle activity ${ }^{15}$. As their study used healthy male adults as a sample, the research subjects differed from our study. Nevertheless, it is conjectured that similar physiological characteristics that appeared during walking in their study, which experimented with different walking environments, manifested in our study as well. Hence, training on sand can diminish muscle fatigue, which is expected to relatively increase gait endurance.

This study has several limitations, one of which is that we could not collect data on actual difference of muscle strength and joint mobility of the affected-side ankle between firm ground and sand. Moreover, we could not check whether more muscle activity was actually induced on sandy ground. Hence, future studies are required to examine the actual change in muscle activity during gait training when using firm ground and sand. Also, there may be differences according to the training of barefoot walking in the experimental group and the wearing of the sneakers during the gait training of the control group. Therefore, future studies need to be compared under the same conditions.

In conclusion, considering that repeated gait training can induce improvement of dynamic balancing ability, regardless of the type of ground, repeated gait training is necessary for patients with stroke. Repeated gait training can improve dynamic balancing ability, as long as patients can walk, regardless of whether they walk in a correct way or walk well.

In the case of gait training that aims at improving gait endurance, repeated gait training on sand is more effective than on firm ground. 
This study is the first research that applied gait training on sand to patients with chronic stroke. The study proposes the possibility of a new approach involving gait training on sand for a variety of subjects, including patients with stroke.

\section{REFERENCES}

1) Muren MA, Hütler M, Hooper J: Functional capacity and health-related quality of life in individuals post stroke. Top Stroke Rehabil, 2008, 15: 51-58. [Medline] [CrossRef]

2) Murtezani A, Hundozi H, Gashi S, et al.: Factors associated with reintegration to normal living after stroke. Med Arh, 2009, 63: 216-219. [Medline]

3) Donnan GA, Fisher M, Macleod M, et al.: Stroke. Lancet, 2008, 371: 1612-1623. [Medline] [CrossRef]

4) Stucki G, Ewert T, Cieza A: Value and application of the ICF in rehabilitation medicine. Disabil Rehabil, 2002, 24: 932-938. [Medline] [CrossRef]

5) Lord SE, Rochester L: Measurement of community ambulation after stroke: current status and future developments. Stroke, 2005, 36: 1457-1461. [Medline] [CrossRef]

6) Lee: The effect of low extremity strengthening enhanced gait mat training on unstable surface on gait parameter and low extremity strength in elderly. J Spec Educ Rehabil Sci, 2011, 50: 419-435.

7) Park YH, Kim YM, Lee BH: An ankle proprioceptive control program improves balance, gait ability of chronic stroke patients. J Phys Ther Sci, 2013, 25: 1321-1324. [Medline] [CrossRef]

8) Impellizzeri FM, Rampinini E, Castagna C, et al.: Effect of plyometric training on sand versus grass on muscle soreness and jumping and sprinting ability in soccer players. Br J Sports Med, 2008, 42: 42-46. [Medline] [CrossRef]

9) Miyama M, Nosaka K: Influence of surface on muscle damage and soreness induced by consecutive drop jumps. J Strength Cond Res, 2004, 18: 206-211. [Medline]

10) Binnie MJ, Dawson B, Arnot MA, et al.: Effect of sand versus grass training surfaces during an 8-week pre-season conditioning programme in team sport athletes. J Sports Sci, 2014, 32: 1001-1012. [Medline] [CrossRef]

11) Podsiadlo D, Richardson S: The timed "Up \& Go": a test of basic functional mobility for frail elderly persons. J Am Geriatr Soc, 1991, 39: 142-148. [Medline] [CrossRef]

12) Mossberg KA, Fortini E: Responsiveness and validity of the six-minute walk test in individuals with traumatic brain injury. Phys Ther, 2012, 92: 726-733. [Medline] [CrossRef]

13) Yiğit SS, Tuncel F: A comparison of the endurance training responses to road and sand running in high school and college students. J Strength Cond Res, 1998, 12: 79-81. [CrossRef]

14) Davies SE, Mackinnon SN: The energetics of walking on sand and grass at various speeds. Ergonomics, 2006, 49: 651-660. [Medline] [CrossRef]

15) Pinnington HC, Dawson B: Running economy of elite surf iron men and male runners, on soft dry beach sand and grass. Eur J Appl Physiol, 2001, 86: 62-70. [Medline] [CrossRef] 